\title{
Discrete Choice Analysis in Hospitality Management Research
}

\author{
Rohit Verma \\ DePaul University \\ Gary M. Thompson \\ Cornell University
}

\begin{abstract}
This article focuses on discrete choice analysis (DCA), which offers an effective approach for incorporating customer preferences into operating decisions in hospitality businesses. First the theoretical background of DCA is presented, including a discussion of how DCA compares to conjoint analysis. The authors then present a guide to designing and conducting a DCA study. Conducting a discrete choice study involves identifying the attributes relevant to customers' choices and the appropriate levels of these attributes, designing an experiment, collecting data and estimating parameters using a multinomial logit model. Finally, the strategic implications of DCA in hospitality management research are discussed.
\end{abstract}

\section{Introduction}

For a firm to increase its market share in a highly competitive hospitality business, it must design its service facilities and service characteristics according to customer preferences. A number of management publications have emphasized the usefulness of integrating the voice of the customer into hospitality businesses, like quick- and full-service restaurants, hotels and recreation facilities. For example, Bowen and Cummings (1990), Lovelock (1992), and Sullivan (1981) advocate an integrated approach to service management and suggest that managers can improve service operations by their awareness and use of marketing constructs and techniques. Several articles also have presented effective approaches for conducting market research and identifying customer choices and preferences. For example, Shoemaker (1994) presents an overview of the different types of marketing research contractors, their strengths and weaknesses, and ways to choose and evaluate them.

Incorporating customer preferences and choices into managerial decisions is very important for quick- and full-service restaurants, hotels and other hospitality businesses because their customers evaluate them on more than one criterion. Because it might not be easy or cost-effective for a hotel or a recreation facility to provide all possible services to its consumers, it is important to understand the relative importance of different customer needs. Information about customer preferences helps management position their service offerings 
based on market needs and their firm's operating capabilities. For example, customers might choose specific quick service restaurants based on the establishment's attributes such as service quality, food cost, food quality, food variety, or speed of delivery. However, it might not be possible for a quick-service restaurant to be a low-cost provider yet provide extensive selection of items. Therefore, it is important to understand how customers trade off among different attributes of quick service restaurants (e.9.. cost, speed, variety, service or quality).

This article presents an effective approach for positioning hospitality services according to customer tastes and preferences. The method presented in this paper, known as Discrete Choice Analysis (DCA), has been successfully used for a variety of applications in marketing, consumer research, transportation, recreation and leisure research, sociology and other social sciences (McFadden, 1986, Louviere and Timmermans, 1990, Verma and Thompson, 1996). The article presents an overview of DCA and discusses various issues related to designing and conducting discrete choice studies.

The rest of the article is divided into the three sections. Presented first is theoretical background of DCA, discussion of the Multinomial Logit Model (used in data analysis), and a description of how DCA differs from Conjoint Analysis. Second, guidelines are presented for designing and conducting a DCA study. Third is discussion of the strategic implications of DCA in hospitality management research.

\section{Discrete Choice Analysis: Theoretical Background}

Discrete Choice Analysis (DCA) is a systematic approach for identifying the relative weights of attributes when a decision maker (e.g., a customer or a manager) chooses an alternative from a set of possible choices. As mentioned earlier, DCA has been used to modol such choice behavior in a variety of academic disciplines. A number of articles and books elaborate on various aspects of DCA. The following section summarizes the main ideas behind the approach. For detailed review of DCA the reader is referred to the texts by Ben-Akiva and Lerman (1991) and Hensher and Johnson (1980) and research articles by Gensch and Recker (1979), Guadagni and Little (1 983), Louviere (1 988), and McFadden (1986).

Past research shows that after acquiring information and learning about the possible alternatives, consumers define a set of determinant attributes to use to compare and evaluate alternatives. After comparing available alternatives with respect to each of the alternatives, the decision makers eliminate some alternatives and develop final choice sets $\left(C_{n}\right)$ containing $n$ altematives. They then form impressions of the various alternatives' positions on the determinant attributes, make value judgments, and combine information to form overall impressions of the alternatives. In forming theiroverall impressions, they have tomake tradeoffs betweenthealtematives' different attributes. The ideas behind thiscomplexchoice process have been proposed by researchers in various academic disciplines (Anderson, 1981, 1982; Ben-Akiva and Lerman, 1991; Louviere. 1988; McFadden, 1986). Figure 1 presents a simple model describing the choice process presented above. 

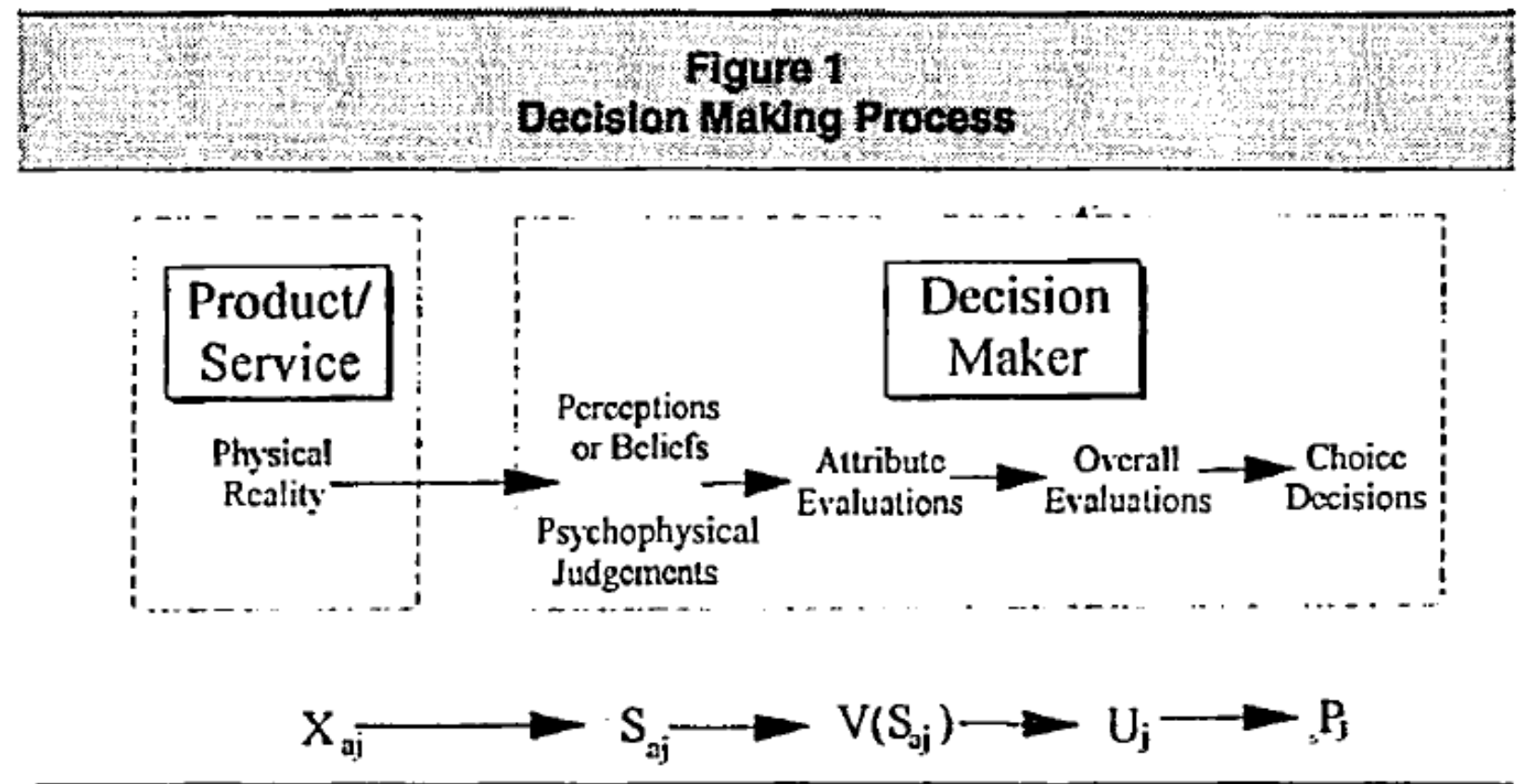

Figure 1 represents choice alternatives as bundles of their attributes. The quantity of physical attribute a present in alternative $j$ is defined as the variable $X_{a j}$ Past research suggests that the decision makers probably do not perceive physical variables. For example, to judge the quality of a quick-service restaurant consumers probably do not actually measure the salt content of its french fries. It is more likely that they make psychophysical or perceptual judgments about the fries' salt content. The parameter $S_{a j}$ in Figure 1 represents the decision maker's subjective perceptions related to the physical variable Xaj.

The remainder of the choice process represented in Figure 1 is based on the Economic Choice Theory and on Information Integration Theory or IIT (Anderson, 1981, 1982; Louviere, 1984, 1988; McFadden 1986). Economic choice theory assumes that individuals' choice behavior is generated by maximization of preferences or utility. Louviere (1 988) defines utility as "judgments, impressions, or evaluations that decision makers form of products or services, taking all the determinant attribute information into account." The idea of utility maximization and its relation to human choice behavior is not new. McFadden (1986) quotes from a 1912 economics text by Taussig:

An object can have no value unless it has utility. No one will give anything for an article unless it yield him satisfaction. Doubtless people are some times foolish, and buy things, as children do, to please a moment's fancy; but at least they think at the moment that there is a wish to be gratified.

IIT suggests that after forming the impressions of the positions of various physical attributes $\left(S_{a j}\right)$ the decision makers make value judgments about the attractiveness (or partworth utility) of each attribute $\left(V\left(S_{a j}\right)\right)$. Next they integrate the information about different determinant attributes to form the overall impression (Utility: $U_{j}$ ) of each alternative. Hence the probability of choosing a particular alternative $\left(P_{j} \mid C_{n}\right)$ is determined by its utility $\left(U_{j}\right)$ Utility 
itself is a function of the decision maker's subjective judgments $\left(V\left(S_{a j}\right)\right)$ of his/her perceptions $\left(S_{a j}\right)$ of the alternative's actual physical attributes $\left(X_{a j}\right)$. Mathematically, the above ideas can be represented as:

$$
\begin{array}{ll}
S_{a j}=f_{1}\left(X_{a j}\right) & \text { for } a \in A, j \in C_{n} \\
V\left(S_{a j}\right)=f_{s}\left(S_{a j}\right) & \text { for } a \in A, j \in C_{n} \\
U_{j}=f_{3}\left(V\left(S_{a j}\right)\right) & \text { for } a \in A, j \in C_{n} \\
\left(P_{j} \mid C_{n}\right)=f_{4}\left(U_{j}\right) & \text { for } j \in C_{n}
\end{array}
$$

where

$A \quad$ is the set of determinant attributes,

$\left(P_{j} \mid C_{n}\right) \quad$ is the probability of choosing alternative $j$ in choice set $n$,

$U_{j} \quad$ is the overall utility of the $j^{\text {th }}$ alternative,

$V\left(S_{a j}\right) \quad$ is the decision makers' subjective judgment of the value (part-worth utility) of alternative $j$ 's attributes $a$,

$S_{a j} \quad$ is the decision maker's perception of alternative $j$ 's physical attribute $a$, and $X_{a j} \quad$ is alternative $j^{\prime}$ s true physical attributes $a$.

Therefore, by algebraic substitution,

$$
\left(P_{j} \mid C_{n}\right)=f_{4}\left(f_{3}\left(f_{2}\left(f_{1}\left(X_{a j}\right)\right)\right)\right)=F\left(X_{a j}\right) \quad \text { for } a \in A, j \in C_{n}
$$

In words, equation (5) represents the probability that an individual will choose an alternative as a function of the alternatives' determinant attributes. Equation (5) also indicates that several different levels of explanation of choice behavior are possible: (i) explanations based on physical variables, (ii) explanations based on belief variables, (iii) explanations using part-worth utilities, and/or (iv) explanations containing combinations of these variables (Louviere, 1988). Most researchers in marketing and other disciplines have chosen to explain consumer choice behavior in terms of determinant attributes of the alternatives (Hensher and Johnson, 1980; Louviere, 1988; Ben-Akiva and Lerman, 1991). Explaining choice behavior in terms of actual attributes of alternatives is valuable for management researchers because, in general, most of these variables can be manipulated by firms.

If the choice set $C_{n}$ contains $n$ alternatives, then from basic probability

$$
0 \leq\left(P_{j} \mid C_{n}\right) \leq 1 \text { for } j \in C_{n}
$$




$$
\text { and } \sum_{j \in C_{n}}\left(P_{j} \mid C_{n}\right)=1.0 \text {. }
$$

Additionally, changing the number of alternatives in a choice set does not change the relative probabilities of choice among the alternatives. This idea is also known as the Independence from Irrelevant Alternatives (IIA) assumption (Ben-Akiva and Lerman, 1991; Louviere, 1988). For example, assume that a few alternatives were added to the choice set $\left(C_{n}\right)$ yielding a new choice set $\left(C_{n}\right)$ containing $n^{*}$ alternatives. Then according to the IIA assumption:

$$
\frac{P_{j} \mid C_{n}}{P_{j} \mid C_{n}}=\frac{P_{j} \mid C_{n *}}{P_{j} \mid C_{n *}}
$$

The above idea can be understood easily by a simple example presented in Ben-Akiva and Lerman (1991). Assume that a commuter rides the bus $50 \%$ of the time and drives a car $50 \%$ of the time. Therefore the choice set contains two alternatives (car and bus). A new bus service is added with exactly the same attributes as the original bus service except for one difference: the buses are red instead of blue. Does this mean that the likelihood of taking the blue bus, the red bus and driving are each $33.3 \%$ ? No; the HA assumption states that if bus color is irrelevant to the commuter, then the probability of selecting the blue bus will be 0.25 , the probability of choosing the red bus will be 0.25 and the probability of driving a car will remain at $0.50^{1}$.

The IIA assumption is extremely important for DCA because it allows researchers to experimentally generate choice sets, estimate the probability of choosing alternatives with given attribute levels and then generalize the results. In other words, since the relative probability of choosing any alternative depends on the relevant attributes of the relevant alternatives, the relative probabilities can be used to estimate the market shares of products (or services). For example, the probability of selecting a subset $C_{n}^{\prime}$ from the original choice set $C_{n}$ will be:

$$
\sum_{j \in C^{\prime} n}\left(P_{j} \mid C_{n}\right)
$$

Hence, the relative probability of choosing any alternative $j$ from sub-choice set $C_{n}^{\prime}$ can be represented as the conditional probability:

$$
\left(P_{j} \mid C^{\prime}{ }_{n}\right)=\frac{\left(P_{j} \mid C_{n}\right)}{\sum_{j \in C^{\prime} n}\left(P_{j} \mid C_{n}\right)}
$$

Therefore, using the conditional probability presented in equation (10) as a function of the alternatives' physical attributes $\left(X_{a j}\right)$ allows one to estimate the probability of choice (or market share). A number of researchers have shown that the conditional probability represented in equation (10) can be expressed as multinomial logit (MNL) model (Ben-Akiva and Lerman, 1991; Gensch and Recker, 1979; Guadagni and Little, 1983; Louviere. 1984; Louviere and Timmermans, 1990; McFadden, 1986). The MNL model is expressed as 


$$
\left(P_{j} \mid C_{n}^{\prime}\right)=\frac{e^{v j \mu}}{\sum_{k=1}^{n} e^{v k \mu}}
$$

where $V_{j}$ represents the systematic component of utility $\left(U_{j}\right)$ of alternative $\mathrm{j}$. The MNL model assumes that the probability of selecting an alternative depends on the decision maker's perceptions of the relative "attractiveness" or "utilities" of the alternatives. The model also assumes that the utilities $\left(U_{j}\right)$ are comprised of systematic component $\left(V_{j}\right)$, which can be estimated, and random error $(\varepsilon)$, which is independent and identically distributed according to a Gumbel distribution with a scale parameter $\mathrm{p}$. Representing a product or service as a bundle of its attributes, and by assuming an additive utility function, an alternative's systematic utility can be calculated as:

$$
V_{j}=\sum_{a \in A} \beta_{a} X_{a j}
$$

where $\beta_{a}$ is the relative utility (part-worth utility) associated with attribute $a$.

There are a number of general approaches to finding the $\beta_{a}$ parameters; in practice, however, the maximum likelihood estimation procedure is used (Ben-Akiva and Lerman, 1991). A maximum likelihood estimator is the value of the $\beta_{a}$ parameters for which the observed sample is most likely to have occurred. If $M$ subjects are asked to choose among $n$ alternatives from $L$ distinct choice sets, then the likelihood function, $\mathcal{L}_{i}$ is represented as:

$$
\mathcal{L}=\prod_{m=1}^{M} \prod_{k=1}^{K} \prod_{j=1}^{n} P_{j l}^{Y j k m}
$$

where

$P_{j k}$ represents the probability of selecting alternative $j$ in the $k$ th choice set, and

$Y_{j k m}=1$, if subject $m$ chooses alternative $j$ in choice set $k 0$, otherwise

Several individual level goodness-of-fit statistics can be calculated for an MNL model. An asymptotic t-statistic, similar to a t-test in the ordinary least square (OLS) regression can be calculated for estimated $\beta_{a}$ parameters. Several likelihood ratio tests (similar to the F-test in OLS regression) can be used to test the overall model. A log-likelihood ratio test is basedon the differences between the natural logarithm of the likelihood function (equation (13)) under two conditions. First, the likelihood ratio is calculated either by assuming an equal probability of choosing any alternative in a choice set or by assuming all $\beta_{a}$ parameters to be zero. This natural logarithm of the likelihood (log-likelihood) value is represented as $\mathcal{L} \mathcal{L}(0)$. Next, the likelihood ratio is calculated again using the estimated pa parameters. This log-likelihood value is called $\mathcal{L} \mathcal{L}(\beta)$. Then, the log-likelihood ratio test is defined as:

$$
-2[\mathcal{L} \mathcal{L}(0)-\mathcal{L} \mathcal{L}(\beta)]
$$

which is $\chi^{2}$ distributed with the degrees of freedom equal to the number of $\beta_{a}$, parameters. Other goodness-of-fit measures, called the Akiake Information Criteria (AIC) and the Consistent Akiake Information Criteria (CAIC), are defined in the following manner: 


$$
A I C=-2[\mathcal{L L}(\beta)-\text { number of } \beta \text { parameters }]
$$

and $C A I C=-2[\mathcal{L L}(\beta)-$ number of $\beta$ parameters $(1+\ln (M)]$.

For a "good" MNL model, both AIC and CAIC should be positive (Ben-Akiva and Lerman, 1991). McFadden's $\rho^{2}$ and adjusted McFadden's $\rho^{2}$ measures (similar to the $R^{2}$ and adjusted $R^{2}$ in Ordinary Least Square regression) are defined in the following manner:

$$
\rho^{2}=1-[\mathcal{L} \mathcal{L}(\beta) / \mathcal{L L}(0)]
$$

Adjusted $\rho^{2}=1-\left[\mathcal{L L}(\beta)-\right.$ number of $\beta_{a}$ parameters $\left.) / \mathcal{L L}(0)\right]$

(note that $0 \leq \rho^{2} \leq 1$ and that $0 \leq$ adjusted $\rho^{2} \leq 1$.)

\begin{tabular}{|c|c|c|}
\hline Criteria & Conjoint Analysis & Discrete Choice Analysis \\
\hline Type of Analysis & Experimental & Experimental \\
\hline Independent Variables & Attributes of the altematives & Altributes of the altematives \\
\hline $\begin{array}{l}\text { Dependent Variable } \\
\text { (respondent's task) }\end{array}$ & Rating or ranking of allcmatives & $\begin{array}{l}\text { Choosing an altemative from a } \\
\text { choice set containing several } \\
\text { alternatives }\end{array}$ \\
\hline Respondent's Tesk complexity & Retatively difficult & Relatively easy \\
\hline Experimental Instrument & Descriptions of alternatives & Choice sets \\
\hline Presentalion of allematives & One alternative at a time & Severai altemalives at a time \\
\hline Experimental Design & $\begin{array}{l}\text { Full or fractional factorial design } \\
\text { of alkernatives }\end{array}$ & $\begin{array}{l}\text { (1) Full or fractional factorial } \\
\text { design of alternatives } \\
\text { (2) Combination of several } \\
\text { experimentelly designed } \\
\text { altematives used to generate } \\
\text { choice sets }\end{array}$ \\
\hline $\begin{array}{l}\text { Complexity in Experimental } \\
\text { Design }\end{array}$ & Relatively Moderate & Relatively Complex \\
\hline Estimation Method & $\begin{array}{l}\text { Rating Data: Ordinary Least } \\
\text { Square Regression } \\
\text { Ranking Data: Nonmetric } \\
\text { Scaling Linear Programming }\end{array}$ & Mulitinomial Logit (MNL) Model \\
\hline Complexity in Data Analysis & $\begin{array}{l}\text { Relatively easy with rating data } \\
\text { Relatively complex with ranking } \\
\text { data }\end{array}$ & Relatively compiex \\
\hline Output & Utility function & Prediction of choices \\
\hline Level of Analysis & $\begin{array}{l}\text { Individual Level. Aggregate level } \\
\text { analysis possible }\end{array}$ & $\begin{array}{l}\text { Agoregate Level. Individual } \\
\text { level analysis not possible. }\end{array}$ \\
\hline Segment Level Analysis & Possible & Possibie \\
\hline Prediction of Market Share & Indirecd (using choice simulators) & Direct, using MNL model \\
\hline $\begin{array}{l}\text { Accuracy in Market Share } \\
\text { Prediction }\end{array}$ & $\begin{array}{l}\text { Generally better than several } \\
\text { other experimental methods } \\
\text { (e.g. multidimentional scaling. } \\
\text { likert-type scales) }\end{array}$ & $\begin{array}{l}\text { (1) Extremely accurate } \\
\text { (2) Generaily better than } \\
\text { Conjoint Analysis }\end{array}$ \\
\hline Aspects of Extemal Validity & $\begin{array}{l}\text { Choice not examined direclly } \\
\text { (rating/ranking one at a lime) }\end{array}$ & $\begin{array}{l}\text { (1) Choices observed directly } \\
\text { (2) Decision maker forced to } \\
\text { make Iradeoffs/comparisons }\end{array}$ \\
\hline
\end{tabular}

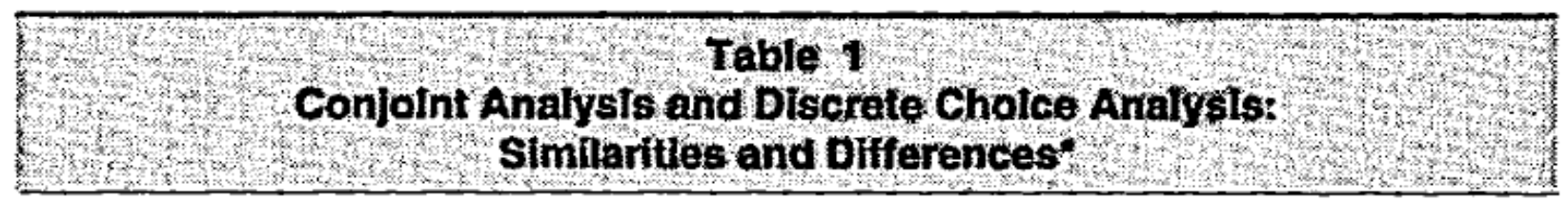

-Comparison based on material in Louviere (1988) and Louviere and Timmermans (1990). 
Discrete choice analysis is often compared with another popular approach known as conjoint analysis (CA), which is also based on consumers' response to experimentally designed profiles of products/services. However DCA and CA differ from each other in terms of their assumptions, statistical theory and data analysis procedures. Recently Louviere and Timmermans (1 990), Elrod et al. (1992) and Horowitz and Louviere (1993) have compared the two methods under a variety of experimental settings. Similarly Moore et al. (1996) have compared market segmentation models based on CA and DCA. Table 1 summarizes the similarities and differences between DCA and CA while Table 2 shows an example of both methods for a study of customer choice of pizza delivery firms ${ }^{2}$.

Broadly speaking, DCA and CA have several similarities: both use experimental design procedures to generate hypothetical products/service profiles and both use their customer preference information to model the market. CA collects data from respondents in the form

\section{Table 2}

\section{A Sample Discrete Choice ${ }^{+}$and Conjoint Task for} Customer Choice of Pizza Delivery Firms

\begin{tabular}{|l|l|l|}
\hline Choice Set \# & Company *1 & Company \#2 \\
\hline Price of First Large Plzza & $\$ 18$ & $\$ 12$ \\
\hline Discount on Second Pizza & $1 / 2$ price & none \\
\hline Promised Delivery Time & 40 mins & 20 mins \\
\hline Actual Delivery Time & can be up to 15 mins late & same as promised \\
\hline Pizza Variety & 3 types of crust & 1 type of crust \\
\hline $\begin{array}{l}\text { Pizza Temperature When } \\
\text { Delivered }\end{array}$ & steaming hot & warm \\
\hline $\begin{array}{l}\text { Unconditional Money Back } \\
\text { Guarantee }\end{array}$ & yes & no \\
\hline
\end{tabular}

Discrete Choice Task for the customers:

\begin{tabular}{|l|l|l|l|}
\hline $\begin{array}{l}\text { IWould Ordor Pizza } \\
\text { From }\end{array}$ & Company \#1 & Company \#2 & Neither \\
\hline
\end{tabular}

Conjoint Task for the customers (Note: Only one of the above two pizza delivery company profiles will be shown to the respendent at a time)

Rate the likelihood of ordering pizza for the above company on the following scale:

1 = will never order pizza from this company

$10=$ will always order pizza from this company

"Verme and Thampeon (1986) used the prone preserted above in theis DCA studf of eustomer choice of pizza deivery frms. 
of ratings (on $\boldsymbol{a}$ predetermined scale-for example 1-100) or rankings of experimental profiles (the respondents do not "choose" any alternative). Generally, researchers assume conjoint data to be on an "equal interval" scale and therefore use ordinary least square regression to estimate the preference model. The preference models' are estimated at the individual level and so the alternatives' market shares are estimated by conducting choice simulations.

In contrast to CA, choice data collected by DCA are assumed to be categorical $(0,1)$ in nature and therefore an MNL model is used for data analyses. Additionally, DCA can only be used to estimate the aggregate data sets. To summarize, then, experimental design, data collection and initial data analysis for individual respondents are easier for conjoint analysis, while it is relatively complicated to use conjoint analysis for predicting aggregate market share. By contrast, experimental design and data analysis are relatively more complex for DCA, but DCA has a high predictive accuracy for aggregate data sets. It is therefore believed that DCA is the more valuable research tool for hospitality researchers.

The preceding paragraphs presented a brief overview of the main ideas behind DCA. We discussed the basic probability choice theory, presented the MNL model used to estimate conditional choice probabilities, introduced several goodness of fit statistical measures, and contrasted DCA and conjoint analysis. The next section presents guidelines for designing and conducting discrete choice studies.

\section{Designed and Conducting Discrete Choice Studies}

Building on the Information Integration Theory (IIT) and economic choice theory, DCA identifies tradeoff (or choice) coefficients for different attributes based on the decision makers' responses to experimentally designed profiles of possible alternatives. Empirical data collected from a random sample of respondents is used to estimate the relative importance of the alternatives' different attributes using a multinomial logit model (MNL). DCA involves designing several experimental profiles (alternatives) of decision situations (e.g., profiles of quick service restaurants with different attributes such as food quality, cost, and delivery time) and asking the decision maker(s) to choose an alternative from a set of possible choices.

A typical discrete-choice experiment simultaneously shows two or more alternatives to the decision maker and asks him/her to choose one (or none). This choice making process is repeated several times. Since the attributes are manipulated by the researcher, the decision maker's choice (dependent variable) can be hypothesized to be affected by the determinant attributes. Next, a multinomial logit (MNL) model is used to identify the weights and statistical significance of the attributes. An MNL model represents the probability of selecting an alternative from a possible set of alternatives. The MNL model assumes that the probability of selecting an alternative depends on the decision maker's perceptions of the relative "attractiveness" or "utilities" of the alternatives.

Over the last 15 years or so, DCA has been used for a number of applications in marketing, transportation, operations management, product design and development, and 
recreation and leisure research. For example, Verma and Thompson (1 996) show how DCA can be used to estimate customer preferences for pizza delivery firms. Earlier Louviere (7984) had presented a similar example for the fast-food industry. Verma (1996) further connects customer preferences to operating characteristics and provides directions for effective pizzadelivery system design. Guadagni and Little (1983) used an MNL model to estimate market share for regular ground coffee using actual purchase data collected by supermarkets using electronic bar code scanners. Louviere and Timmermans (1990) present a review of various DCA studies conducted in recreation research. Ben-Akiva and Lerman (1991) provide a number of examples of DCA in transportation research.

Similar to researchers in-a number of academic disciplines, hospitality management researches are interested in human choice behavior. For example, it is extremely important for a hotel or a quick- or full-service restaurant to understand the relative importance of various service attributes from their customers' point of view. They are also interested in knowing the effect of a given service configuration on customer demand and on management's ability to meet customer needs. Therefore, the authors believe that knowledge of DCA will be extremely valuable for effective hospitality management. Designing and conducting a discrete choice study involves the following steps: identifying attributes; specifying attribute levels; designing an experiment; presenting alternatives to respondents; and estimating an MNL model. The following sections expand on these steps. To keep the discussion focused and concise, detailed examples of DCA are not presented. However, in order to explain certain concepts occasionally examples are used from the fast food and/or pizza industry. For detailed examples of actual DCA studies see Louviere (1984) and Verma and Thompson (1996).

\section{$\underline{\text { Identifying Attributes }}$}

To develop a discrete choice study, start by identifying the determinant attributes used in the decision makers' evaluation processes. Great care must be taken to ensure that all (or at least as many as possible) of the determinant decision attributes are identified and expressed in terms understood by the individuals to be studied. Qualitative market surveys, interviews, case studies, and/or focus groups can be conducted to identify a set of such relevant attributes. A small number of informal interviews can be conducted to short-list the relevant attributes. $A$ review of the practitioner and academic literature relevant to the study might also be necessary.

To avoid a trivial study the final number of attributes selected should not be very small. At the same time, the number of attributes should not be very large because it increases the dimensionality of the study. According to Louviere and Timmermans (1990), one must consider the following when building a list of attributes: (1) Is it necessary to include an exhaustive list of all salient attributes? (2) Which attributes can be retained, recombined, or re-expressed to keep the set of attributes as non-redundant and as small as possible to make the experiment tractable? For example, Verma and Thompson (1996) interviewed a number of randomly selected customers of pizza delivery firms and identified seven determinant attributes: price; 
discount on second pizza, promised delivery time, actual delivery time, types of pizza crust, pizza temperature, and unconditional money-back. Based on extensive discussion sessions, trade literature, and interviews with the managers, Louviere (1984) identified five determinant attributes for quick service restaurants.

The basic DCA can be easily modified/adapted to situations which require a large number of attributes. Louviere and Timmermans (1990, 1992), Timmermans (1981) and Oppewal et al. (1994) have developed hierarchical choice experiments which can be used to estimate choice decisions involving a large number of attributes. The reader is referred to Louviere, Oppewal, Timmermans, and Thomas (1994) for a detailed review of various approaches involving large number of attributes in discrete choice studies.

\section{Specifying Attributes Levels}

Often the attribute ranges are chosen so that they either span the actual values observed in the marketplace and/or represent the expected values to be used during the planning horizon. Sometimes, the range of attributes is fixed by physical constraints or legal reasons. For example, government regulations might restrict the price of an alternative. The range of an attribute should not be so large that the choice experiment becomes unrealistic or the respondents have difficulty visualizing it. Response reliability suffers if unrealistic attribute ranges are used.

Next, the attribute range is divided into two or more levels for the purpose of experimental design. Using two levels for each variable (lowest and highest possible value of an attribute) makes designing the experiment easy and is generally sufficient to estimate the linear effect of the attributes on choice. One needs more than two levels to estimate an attribute's nonlinear effect on choice. Increasing the number of levels necessitates more complex experimental designs, as explained below. On the other hand, experiments with multiple levels allow the researcher to model the choice process more accurately. Hagerty (1986) states that complex models predict the aggregate market share of actual products/services more accurately than simple models. It is therefore recommended that the hospitality researchers weigh the costs and benefits before choosing the number of levels and experimental design. For most of the exploratory studies or products/services with a large number of attributes, two levels might be acceptable. For more advanced studies and/or studies with relatively few determinant attributes, the researchers should use more levels.

\section{Experimental Design}

The design of a discrete choice experiment involves combining the levels of the determinant attributes and generating profiles of possible alternatives. Each attribute represents a factor in the experimental design. Factorial experimental designs allow one to create descriptions of choice alternatives in such a way that all of the statistical effects of the attributes that are varied can be estimated independently. In practice, however, complete factorial designs rarely are used because of the large number of possible combinations. Instead, 
fractional factorial designs are used to construct a limited number of profiles. Fractional factorial designs assume that one or more interactions among the independent variables (attributes) are not statistically significant. This is not a bad assumption because generally the

"main effects" account for the most of the variation in the dependent variables. We recommend selecting experimental designs which estimate all the main effects and two-way interactions among a few variables. For example, Verma and Thompson (1996), using a fractional factorial design, generated 16 orthogonal profiles of pizza delivery companies. The experimental design allowed them to estimate the main effects of all determinant attributes and (a few) selected two-way interactions. Please refer to the following statistics and experimental design-related publications for discussions on fractional factorial designs with different properties (Bishop, Fienberg, and Holland, 1991; Hahn and Shapiro, 1966; Louviere, 1988; McLean and Anderson, 1984).

Next, several experimentally generated profiles are grouped together to generate choice sets. According to Louviere (1988), the design used to generate choice alternatives need not be an experimental design; in fact, it need only be a list of competing alternatives. Such a list might include all products (or services) competing in a particular product class or existing products and set of new product concepts that might be introduced. To the authors' knowledge, there is no agreement on the best method for generating 'the most efficient choice sets (see, for example, the texts by Ben-Akiva and Lerman (1991), Hensher and Johnson (1980) and Louviere and Woodworth (1983).

Verma and Thompson (1996) used two levels for their pizza study and therefore were able to combine a particular experimental profile with its "foldover" design to create a choice set. A foldover design contains the opposite levels of every attribute for a given profile. For example, an experimental profile containing a pizza price of $\$ 18$ and a $50 \%$ discount on a second pizza was combined with a competing profile having a pizza price of $\$ 12$ and no discount on a second pizza. Thus, $\$ 12$ and $\$ 18$ represented the two levels of one factor and the $50 \%$ and $0 \%$ discount represented the two levels of a second factor in their study.

\section{Presentation of Alternatives to Respondents}

A wide range of media can be used to describe hypothetical choice alternatives generated by the experimental design. For example, one may use sentences, short phrases, or paragraphs; pictures, drawing, photographs, or computer images; models; or any combination of written, visual or other sensory representation. The choice of presentation media is situational and the best medium for one study might be not be appropriate for another.

The final aspect of designing discrete choice experiments involves selecting the choice task. Most of the DCA studies reported ii; the literature show two or more alternatives to the decision maker at a time and ask him/her to choose one (or none) of the alternatives (Louviere, 1988; Louviere and Timmermans, 1990). It is also possible to show only one experimental profile to the decision maker at a time and ask a yes/no choice question. Finn and Louviere 
(1992) recently used another choice task known as the "best-worst" procedure in which the respondent not only chooses an alternative from a given choice set but also chooses the "best" and the "worst" attributes of a profile.

\section{Estimating an MNL Model}

After generating the discrete choice sets and deciding the choice task, empirical data are collected from multiple respondents. It is important to select respondents which are representative of the population of interest. Otherwise the results obtained from the study will not be generalizable to the whole population. The researcher can either ask all the subjects to respond to all different choice sets generated by the experimental design, or divide the choice sets into two or more statistically equivalent subsets and then ask a particular subject to only respond to one choice subset. No agreement exists on the ideal number of choice sets per respondents. Some researchers believe that the reliability of choice data is reduced if a particular respondent is asked to make a very large number of choices. Others believe that obtaining a large number of choice responses from every individual improves the reliability of parameter estimates simply because more information is collected from every subject.

Empirical data collected from the respondents for any discrete choice experiment are categorical in nature. This happens because the respondent is asked to choose only one alternative (normally coded as 1 ; all other alternatives coded as 0 ) from every choice set. Additionally, one cannot estimate discrete choice models for single individuals because there are too few observations/individual to satisfy the asymptotic conditions needed to obtain consistent and efficient parameter estimates. Satisfaction of asymptotic properties ordinarily requires large numbers of observations of discrete choices (at least 10 respondents). Therefore responses from various subjects are aggregated and choice frequencies are used to estimate MNL models.

Since the discrete choice data are categorical in nature, the multinomial logit model (equation (11)) is used to estimate the choice probabilities. Although there are a number of approaches for estimating parameters, maximum likelihood procedure is used in practice. This procedure estimates the MNL model for which the observed choice frequencies are most likely to have occurred. A number of software programs are available which can estimate MNL models for the discrete choice data. These programs estimate the $\beta$ parameters (equation 12) based on an MNL model (equation 11) and then calculate various goodness-of-fit statistics (equations (13)-(18)). The authors have used the NTELOGIT (Intelligent Marketing Systems, 1992), LIMDEP (Econometric Software, 1995) and FOXLOGIT (Woodworth, Gilbert and Fox, 1990) programs in our research projects. FOXLOGIT is a FORTAN program which requires input data files containing choice frequencies in certain input format. NTELOGIT is a menu driven program which allows the users to input data in various formats. NTELOGIT can perform several advanced statistical analysis in addition to estimating the MNL model. For example, NTELOGIT can test if any two MNL models are statistically equivalent of each other using a Gumbel scale hypothesis testing procedure (Swait and Louviere, 1993). LIMDEP is a generalized econometric 
package that can perform a number of statistical analyses, including MNL for discrete choice data. All these programs have been used by various researchers and are very reliable.

\section{Discussion}

Understanding the choice behavior of customers and managers is extremely important for effective hospitality management because this knowledge provides insights into the decision-making processes used by individuals. By understanding and using consumer choice modeling, managers can position their service offerings to better suit market needs. Mathematical models representing consumer choice can be easily linked to several operating decisions (e.g., labor scheduling, special activities planning, menus selection) and optimal service configurations can be identified for further improvement in hospitality businesses. The authors believe that knowledge of discrete choice analysis will help both academic researchers and practicing managers in achieving these goals. The remainder of this section contains discussion of possible uses of discrete choice analysis in hospitality businesses.

Although the development of an MNL model requires in-depth knowledge of statistical principles, one can easily implement a spreadsheet-based decision support system based on the MNL model. Verma and Thompson (1996) show a simple example of such a decision support system for pizza delivery firms. Researchers can program a spreadsheet to estimate the probability of selecting alternatives based on estimated $\beta$ weights. Managers then only have to input the actual attributes of their and their competitors' products to calculate their (and their competitors') expected market share. Verma and Thompson's (1 996) example shows the expected market share for three pizza delivery firms (with different levels of determinant attributes) operating in a given geographic area. Researchers report that these estimates are very accurate (Ben-Akiva and Lerman, 1991; McFadden, 1986; Verma, 1996). The decision support system can also be used to estimate the impact of changing the level of one or more attributes by any one business and/or their competitors. In fact the dynamic nature of actual marketplace can be very effectively modeled in a spreadsheet. The managers can easily evaluate multiple business, operating and/or marketing strategies using such a decision support system.

The predictive power of DCA-based MNL models can be further improved by market segmentation techniques. In a recent study, Moore et al. (1996) show that a latent segment (LS) procedure based on discrete choice analysis outperforms several other market segmentation techniques. Moore et al.'s (1996) procedure assigns consumers to different market segments based on their actual choice behavior and therefore predicts actual markets very well.

The MNL models also can be used as training tools for positioning managers' perceptions of customer needs according to customers' actual needs. Often managers' of large service organizations are far removed from their firm's customers and/or too busy managing day-to-day operations, resulting in a gap between what they think customers need and what customers actually need. Such "perception-choice" gaps can be easily identified by comparing 
two MNL models, one for customer choices and the other for managers' perceptions for customer choices. Swait and Louviere (1993) have developed a statistical test (based on the $\chi^{2}$ distribution) for comparing two MNL models.

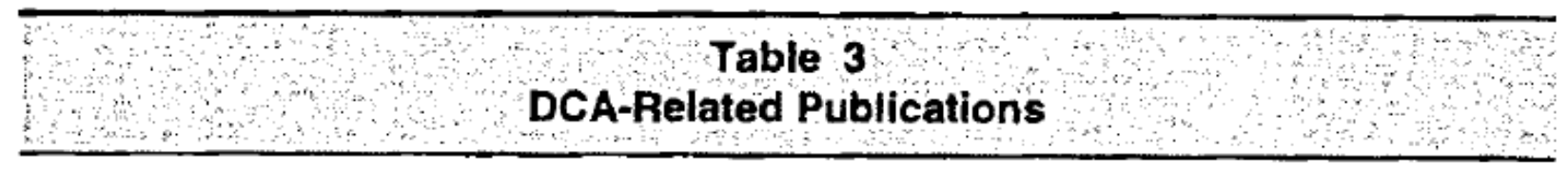

\begin{tabular}{|c|c|}
\hline Software Programs & $\begin{array}{l}\text { Econometric Software (1996) } \\
\text { Intelligent Marketing Systems (1992) } \\
\text { Woodworth, Gilbert and Fox (1990) }\end{array}$ \\
\hline DCAMethodology-related & $\begin{array}{l}\text { Ben-Akiva and Lerman (1991) } \\
\text { Finn and Louviere (1992) } \\
\text { Gensch and Recker (1979) } \\
\text { Hegerty (1986) } \\
\text { Hensher and Johnson (1980) } \\
\text { Louviere and Timmermans (1990, 1992) } \\
\text { Louviere, Oppewal, Timmermans, and Thomas (1994) } \\
\text { McFadden (1986) } \\
\text { Swait and Louviere (1993) }\end{array}$ \\
\hline DCA Examples & $\begin{array}{l}\text { Guadagni and Little (1983) } \\
\text { Louviere (1984) } \\
\text { Oppewal, Louviere and Timmermans (1994) } \\
\text { Pullman (1996) } \\
\text { Punj and Staelin (1978) } \\
\text { Verma and Thompson (1996) }\end{array}$ \\
\hline Conjoint Analysis and DCA & $\begin{array}{l}\text { Carmone and Green (1981) } \\
\text { Elrod, Louviere and Davey (1992) } \\
\text { Green, Carroll and Goldberg (1981) } \\
\text { Green and Srinivasan (1990) } \\
\text { Horowitz and Louviere (1993) } \\
\text { Louviere (1988) }\end{array}$ \\
\hline $\begin{array}{l}\text { Market Segmentation using } \\
\text { Discrete Choice or Conjoint } \\
\text { Data }\end{array}$ & $\begin{array}{l}\text { Currim (1981) } \\
\text { DeSarbo, Wedal, Vriens and Ramaswamy (1992) } \\
\text { Dillon, Kumar, Smith de Borrero (1993) } \\
\text { Gensch (1985) } \\
\text { Green and Krieger (1991) } \\
\text { Moore, Gray-Lee and Louviere (1996) } \\
\text { Zenor and Srivastave (1993) }\end{array}$ \\
\hline
\end{tabular}

The customer choice information obtained from DCA can be used for designing services and/or effectively managing process' operations in hospitality businesses. For example, assume that customers of a particular quick-service restaurant assign more weight to waiting time relative to the number of food items on the menu. It is clear then that the managers should focus their attention of scheduling labor force and/or streamlining operations to reduce waiting time. The managers might also consider reducing the number of items on the menu to speed up the order preparation cycle. The MNL model can predict the impact of each of these 
strategies. A colleague of the authors is currently working on a problem related to customer choice and waiting time in the ski industry. She is using the choice data and a sophisticated computer simulation model to evaluate the best choices for capacity expansion and target markets for a particular ski resort (Pullman 1996).

Overall, the authors believe that DCA contributes to the knowledge of hospitality research by suggesting a new approach for effective management. The proposed approach can be used as a starting point for implementation of an effective process improvement approach. Discrete-choice analysis can be used to identify relative weights for product/service attributes from customers' points of view.

The objective of this study was to present an overview of discrete choice analysis and to show how one can use DCA to effectively integrate customer preferences and choices into operating decisions in hospitality businesses. This study presented the theory, methodology, cited various examples, and have demonstrated the usefulness of DCA as a decision support tool in hospitality management research. The authors feel that the use of customer-based approaches similar to the one presented here can significantly improve the financial and market position of firms operating in competitive hospitality industries. For further reading, please refer to Table 3 which contains brief descriptions of various publications related to Discrete Choice Analysis.

\section{Notes}

${ }^{1}$ Clearly it is possible that the probability of driving a car will change. For example, if the commuter drives the car only on the days when the bus is crowded, and the new bus service reduces crowding, then the likelihood of the commuter driving a car to work will fall below $50 \%$ and the probability of his/her riding either bus will rise $50 \%$. Obviously, then the IIA must apply to all relevant characteristics of an alternative.

${ }^{2}$ See Verma and Thompson (1996) for details of the study using the DCA profile presented in Table 2.

\section{References}

Anderson, N.H. (1981). Foundations of information integration theory, New York Academic Press.

Anderson, N.H. (1982). Methods of information integration theory, New York Academic Press.

Ben-Akiva, M., \& Lerman, S.R. (1991). Discrete choice analysis, Massachusetts: The MIT Press.

Bishop, Y.M.M, Fienberg, S.E., \& Holland, P.W. (1991). Discrete multivariate analysis: Theory and practice. Massachusetts: The MIT Press.

Bowen, D.E. \& Cummings, T.G. (1990). Suppose we took service seriously. Service management effectiveness, Jossey-Bass Publishers, 1-4. 
Carmonc, F.J. \& Green, P.E. (1987). Model misspecification in multiattribute parameter estimation. Journal of Marketing Research, 78 (2), 87-93.

Currim, I.S. (1981). Using segmentation approaches for better prediction and understanding from consumer mode choice models. Journal of Marketing Research, 18, 301-309.

DeSarbo, W.S., Wedel, M., Vriens, M., \& Aamaswamy V. (1992). Latent class metric conjoint analysis. Marketing Letters, 3, 273-289.

Dillon, W.R., Kumar, A., \& Smith de Borrero, M. (1993, Feb.). Capturing individual differences in paired comparisons: An extended btl model incorporating descriptor variables. Journal of Marketing Research, 42-51.

Econometric Software. LIMDEP: Program and user guide, New York, 1996.

Elrod, T., Louviere, J.J., \& Davey, K.S. (1992). An empirical comparison of rating-based and choice-based conjoint models. Journal of Marketing Research, 29, 368-377.

Finn, A., \& Louviere, J.J. (1992). Determining the appropriate response to evidence of public concern: The case of food safety. Journal of Public Policy and Marketing, 11 (I), 12-25.

Gensch, D.H. (1985). Empirically testing a disaggregate choice model for segments. Journal of Marketing Research, 22, 462-467.

Gensch, D.H., \& Recker, W.W. (1979). The multinomial, multiattribute logit choice model. Journal of Marketing Research, 16 (2), 124-132.

Green, P.E., \& Srinivasan, V. (1990, Oct.). Conjoint analysis in marketing: New developments with implications for research and practice. Journal of Marketing, 3-1 9.

Green, P.E., \& Krieger, A.M. (1991, Oct.). Segmenting markets with conjoint analysis. Journal of Marketing, 20-31.

Guadagni P.M., \& Little, J.D. (1983). A logit model of brand choice calibrated on scanner data. Marketing Science, 2 (3), 203-237.

Hagerty, M. R. (1986). The cost of simplifying preference models. Marketing Sciences, 5 (4), 298-319.

Hahn, G.J., \& Shapiro, S.S. (1966). A catalog and computer program for the design and analysis of orthogonal symmetric and asymmetric fractional factorial experiments. New York: General Electric Research and Development Center.

Hensher. D.A., \& Johnson, L. (1980). Applied discrete choice modeling, London: Croom-Helm.

Horowitz J.L., \& Louviere. J.J. (1993). Testing predicted choices against observations in probabilistic discrete-choice models. Marketing Science, 
Intelligent Marketing Systems, CONSERV, Software program and user's manual, Edmonton, Canada, 1992

Intelligent Marketing Systems, NTELOGIT, Software program and user's manual, Edmonton, Canada, 1992

Louviere, J.J. (1988). Analyzing decision making: Metric conjoint analysis. Newbury Park, California: SAGE Publications.

Louviere, J.J. (1984). Using discrete choice experiments and multinomial logit choice models to forecast trail in a competitive retail environment: A fast food restaurant illustration. Journal of Retailing, 60 (4), 81-107.

Louviere, J.J. (1988, January). Conjoint analysis modeling of stated preferences. Journal of Transport Economics and Policy, 93-1 19.

Louviere, J.J., \& Woodworth, G.G. (1983). Design and analysis of simulated consumer choice or allocation experiments: An approach based on aggregate data. Journal of Marketing Research, 20, 350-367.

Louviere, J.J., \& Timmermans, H. (1990). Stated preference and choice models applied to recreation research: A review. Leisure Sciences, 12. 9-32.

Louviere, J.J., \& Timmermans, H. (1990). A review of recent advances in decompositional preference and choice models. Journal of Economic and Social Geography, 81 (3), 214224.

Louviere, J.J., \& Timmermans, H. (1992). Testing the external validity of hierarchical conjoint analysis models of recreational destination choice. Leisure Sciences, 14, 179-194.

Louviere, J.J., \& Timmermans, H. (1990). Using hierarchical information integration to model consumer responses to possible planning actions: Recreation, destination choice illustration. Environment and Planning, 22, 291 - 308.

Louviere, J.J., Oppewal, H., Timmermans, H., \& Thomas, T. (1994). Handling large number of attributes in conjoint analysis: Who says existing techniques can't be applied? But if you want an alternative, how about hierarchical choice experiments? Working Paper.

Louviere, J.J., \& Timrnermans, H. (1990). Stated preferences and choice models applied to recreation research: A review. Leisure Sciences, 12.9-32.

Lovelock, C.H. (1992). A basic toolkit for service management. Managing services: Marketing, operations, and human resources, (Second Edition), Englewood Cliffs, New Jersey: Prentice Hall.

McFadden, D. (1986).The choice theory approach to marketing research. Marketing Science, 5 (4), 275-297. 
Moore, W.L., Gray-Lee, J., \& Louviere, J.J. (1996). A cross-validity comparison of conjoint analysis and choice models at different levels of aggregation. Working Paper, David Eccles School of Business, University of Utah, May.

McLean, R., \& Anderson, V. (1984). Applied factorial and fractional designs. New York: Marcel Deckker.

Oppewal H. Louviere, J.J., \& Timmermans, H.J.P. (1994, February). Modeling hierarchical conjoint processes with integrated choice experiments. Journal of Marketing Research, 3 7, 92-105.

Pullman, M.E. (1996). Optimal service design: Integrating marketing and operations elements for capacity decisions. Working paper, Colorado State University.

Punj G.N., \& Staelin, R. (1978, November). The choice process for graduate business schools. Journal of Marketing Research, 75, 588-598.

Sullivan, R.S. (1981). The service sector: Challenges and imperatives for research in operations management. Journal of Operations Management, 2 (4), 211-214.

Shoemaker, S. (1994). Understanding the marketing research process: A guide to using an outside research supplier. International Journal of Hospitality Management, 73 (I), 3956.

Swait, J. \& Louviere, J.J. (1993, August). The role of the scale parameter in the estimation and comparison of multinomial logit models. Journal of Marketing Research, 30, 305-314.

Timmermans, H. (1981). Consumer choice of shopping center: An information integration approach. Regional Studies, 76 (3). 171-182.

Verma R. (1996). A model for effective operations management integrating constrainedoptimization theory and customer choice patterns, Ph. D. dissertation, University of Utah.

Verma. R., \& Thompson, G.M. (1996). Basing service management on customer determinants: The importance of hot pizza, Cornell Hotel and Restaurant Administration Quarterly, 37 (3), 18-23.

Woodworth, G.G., Gilbert, C., \& Fox, M.F. (1990). Documentation for the LOGIT program to estimate multinomial logit models.

Zenor, M.J., \& Srivastava, R.K. (1993). Inferring market structure with aggregate data: A latent segment approach. Journal of Marketing Research, 30 (3), 369-379. 


\section{Submitted August 5, 1996}

First Revision Submitted October 1, 1996

Second Revision Submitted November 11, 1996

Accepted November 20, 1996

Refereed Anonymously

Rohit Verma, Ph.D., is a visiting assistant professor in the Department of Management, DePaul University (Chicago, IL 60604; e-mail: rverma@wppost.depaul.edu) and Gary M. Thompson, Ph.D., is an associate professor of Operations Management in the School of Hotel

Administration, Cornell University (Ithaca, NY 14853; e-mail: gmtl @cornell.edu). The authors thank Stowe Shoemaker and two anonymous reviewers for providing valuable suggestions for improving this paper. The authors also thank Jordan Louviere for providing important references and background materials related to both conjoint and discrete choice analysis. 